\title{
Crohn's disease in the elderly: Clinical presentation and manifestations from a tertiary referral center in Turkey
}

\author{
Fatih Saygili,, ${ }^{1}$ Saba Mukaddes Saygili, ${ }^{2}$ Ilyas Tenlik, ${ }^{1}$ Mahmut Yuksel, ${ }^{1}$ \\ Zeki Mesut Yalin Kilic, ${ }^{1}$ Yasemin Ozderin Ozin, ${ }^{1}$ Ertugrul Kayacetin ${ }^{1}$ \\ ${ }^{1}$ Department of Gastroenterology, Turkiye Yuksek Ihtisas Training and Research Hospital, Ankara, Turkey \\ ${ }^{2}$ Department of Reanimation and Intensive Care, Ankara University Faculty of Medicine, Ankara, Turkey
}

\begin{abstract}
OBJECTIVE: There is no precise consensus at present on age to define elderly patients with inflammatory bowel disease (IBD), but recently, age of more than 60 years has been widely accepted. Characteristics of IBD in the elderly are somewhat different from what is seen in younger patients. The elderly have milder disease activity, and therapeutic options are fewer because of their age and features such as comorbidities, drug interactions, and loss of organ function. There are few reports on Crohn's disease in the elderly. Herein, first report on this topic with respect to population of this country is presented.
\end{abstract}

METHODS: Characteristics of 95 patients with Crohn's disease, who were over age 60 from 3125 patients with IBD treated in our clinic between 1996 and 2015 were analyzed. Research was performed using patient files, and outpatient clinic visits, when possible.

RESULTS: Median age of the group was 66 years, and male:female ratio was 1.6 . Of the total, $48.4 \%$ of the patients had colonic disease, $37.9 \%$ had ileocolonic disease, and $13.7 \%$ had small bowel disease. Data indicated that $23.1 \%$ of patients had undergone surgical procedures, which were primarily right hemicolectomy and ileotransversostomy. Disease was most often managed with mesalazine or azathioprine. It was also determined that $12.6 \%$ patients had 2 or more comorbidities, and findings indicated coronary heart disease and hypertension were most prevalent.

CONCLUSION: Analysis revealed similar features in characteristics of disease compared with recent knowledge reported in the literature. This is the first report from our country to describe Crohn's disease in the elderly population, and the number of patients is sufficient to provide general information about this group.

Keywords: Crohn's disease, clinical features; elderly.

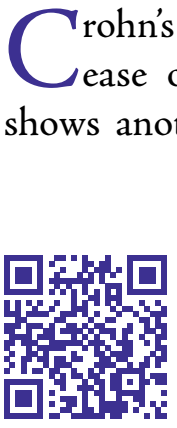

age [1]. Elderly onset or presentation of disease demonstrates differences in terms of clinical presentation, diagnosis, clinical course, and complications

Received: October 10, 2016 Accepted: December 19, 2016 Online: January 23, 2017

Correspondence: Dr. Fatih SAYGILI. Turkiye Yuksek Ihtisas Egitim ve Arastirma Hastanesi, Gastroenteroloji Klinigi, Sihhiye, Ankara, Turkey.

Tel: +90 312 - 3061000 e-mail: fsaygili2014@gmail.com

(c) Copyright 2016 by Istanbul Northern Anatolian Association of Public Hospitals - Available online at www.kuzeyklinikleri.com 
of both the disease and treatment when compared with early onset disease [2]. These differences have been reported in studies of European and American population in a few publications, but there is currently no data from our country about clinical course among the elderly [3]. Turkiye Yuksek Ihtisas Education and Research Hospital has an individual IBD outpatient clinic and is a tertiary referral center for Turkey. This report is retrospective analysis of data of 95 patients with Crohn's disease who were over age of 60 years of age. Analysis was performed to establish definitive data that would reflect clinical features and course of the patients, and local results obtained were compared with literature data to investigate any possible local differences.

\section{MATERIALS AND METHODS}

Records of 3125 patients with diagnosis of IBD who were treated in our clinic between 1995 and 2016 were screened, and data of 95 patients with Crohn's disease who were older than 60 years of age were analyzed. All of the patients had diagnosis of Crohn's disease after the age of 60 , according to the files retrieved from the clinic. Date of diagnosis, treatment schedule, and clinical course and follow up were analyzed using special handwritten file system and electronic medical information system of the clinic. Observed and demographic features of the patients were reported as definitive data, and as there was no applicable comparison, statistical difference was not calculated. These definitive data describing clinical course and features of the patients were obtained to provide local report on elderly patients with Crohn's disease.

\section{RESULTS}

Median age of 95 patients was 66 years, and male:female ratio was $1.6: 1$. Demographic characteristics are summarized in Table 1 . Colonic involvement was most prevalent in terms of localization, with incidence of $48.4 \%$. Ileocolonic disease was present in $37.9 \%$, and small intestinal involvement was observed in $13.7 \%$. None of the patients had perianal disease or fistula. Mean follow-up time was 38 months (range: $14-62$ months).

When treatment modalities were considered, preferred medications reflected relatively milder clinical course $\$ 89.5 \%$ of the patients were using oral mesalazine, and azathioprine use was $56.8 \%$. Only 2 patients $(2.1 \%)$ were treated with adalimumab, as they were observed to have relapsing disease at site of ileotransversostomy following right hemicolectomy. None of the patients reported any serious adverse effects due to their medications. Surgical therapy was observed to be necessary in $23.1 \%$ of the patients, and all cases were ileotransversostomy following right hemicolectomy due to severe ileocaecal involvement and fibrotic narrowing.

More than 2 comorbidities were observed in $12.6 \%$ patients. Hypertension and coronary heart disease were most common; however, these comorbidities did not affect treatment of Crohn's disease.

There were no patient deaths in the group during the study period.

\section{DISCUSSION}

Definition of IBD in the elderly is widely accepted as patients older than 60 years who have IBD. $\mathrm{Pa}$ tients diagnosed after age of 60 as well as previously diagnosed patients who have reached or exceeded this age have increasing importance in terms of clinical follow-up and treatment strategies. Incidence of IBD in the elderly was reported to be between 4 and 8/100000 in an American and European population study [4]. Clinical features tend to be different in elderly patients compared with young adults. Most common features in the young, such as diarrhea, abdominal pain, and anemia, tend to be less frequent, whereas loss of weight, bleeding, fever, and paradoxically, constipation are more common symptoms in the elderly with Crohn's disease [5]. Elderly onset of the disease has milder activity with more stable clinical course. For example, stricturing and fistulating disease with ileocolonic involvement is comparably less frequent than in young individuals [6]. However, despite milder disease activity, comorbidities, drug interactions, and increasing organ dysfunction can be problematic and management of the patients and treatment strategies can still be challenging. 
TABLE 1. Demographic and clinical features of the patients

\begin{tabular}{|c|c|c|c|c|}
\hline & \multicolumn{2}{|c|}{$\begin{array}{l}\text { Elderly population } \\
\qquad(\mathrm{n}=95)\end{array}$} & \multicolumn{2}{|c|}{$\begin{array}{l}\text { Remaining Crohn's } \\
\text { patients ( } n=1092)\end{array}$} \\
\hline & $\mathrm{n}$ & $\%$ & $\mathrm{n}$ & $\%$ \\
\hline Age (years) & \multicolumn{2}{|c|}{ 60-82 (median: 66) } & \multicolumn{2}{|c|}{$18-60$} \\
\hline \multicolumn{5}{|l|}{ Gender } \\
\hline Male/Female & \multicolumn{2}{|c|}{$59 / 36$} & \multicolumn{2}{|c|}{$536 / 461$} \\
\hline \multicolumn{5}{|c|}{ Localization (Montreal classification) } \\
\hline L1 & 13 & 13.7 & 390 & 35.7 \\
\hline L2 & 46 & 48.4 & 242 & 22.2 \\
\hline L3 & 36 & 37.9 & 460 & 42.2 \\
\hline \multicolumn{5}{|c|}{ Behavior (Vienna classification) } \\
\hline B1 & 91 & 95.8 & 580 & 53.1 \\
\hline B2 & 4 & 4.2 & 239 & 21.9 \\
\hline B3 & \multicolumn{2}{|c|}{ none } & 93 & 8.5 \\
\hline Perianal disease & \multicolumn{2}{|c|}{ none } & 198 & 18.1 \\
\hline \multicolumn{5}{|l|}{ Treatment } \\
\hline 5-Aminosalicylate & 82 & 89.5 & 929 & 85.1 \\
\hline Azathioprine & 54 & 56.8 & 707 & 64.7 \\
\hline Biologic & 2 & 2.1 & 282 & 25.8 \\
\hline Surgery & 22 & 23.1 & 309 & 28.3 \\
\hline Diabetes & 13 & 13.7 & 78 & 7.1 \\
\hline Coronary heart disease & 21 & 22.1 & 53 & 4.9 \\
\hline Hypertension & 36 & 37.9 & 156 & 14.3 \\
\hline Pulmonary disease & 8 & 8.4 & 35 & 3.2 \\
\hline
\end{tabular}

We aimed to investigate clinical features and follow-up of patients with Crohn's disease who were older than 60 years of age. This is the first report to examine this topic in Turkey.

Our local clinical findings, such as involvement, clinical presentation, and treatment choices were similar to results previously reported in the literature.

It is easily observed that Crohn's disease behaves a little differently in the elderly compared with younger individuals. Natural course of the disease is different, apart from additional clinical characteristics of an elderly patient. Principal difference is localization of the disease, which is more prominent in colonic region. In our population, this was comparably different from younger individuals in our database. This is also reported in the literature. In a study from Hungary conducted by Lakatos et al., incidence of Crohn's disease in the elderly was 4/100000 annually. Colonic involvement was reported to be most common, and clinical course did not demonstrate difference according to Montreal classification system [7]. Absence of perianal disease and strictures are the other main diversions from what is typically seen in younger population. These facts are directly responsible for disease severity, and absence of these behavioral aspects can be beneficial side of Crohn's disease in the elderly. On the other hand, presence of comorbidities can make treatment of this population challenging. As the clinical disease activity is milder, with very low rate of perianal disease, fistulation, or severe strictures, and with colonic involvement more common, need for use of biologics is less frequent in this group of patients [8]. Present study results regarding biologic use 
can be largely explained by this fact. This can lead to fewer drug interactions and relatively lower risk of adverse drug effects [9]. Furthermore, due to this milder clinical course and the character of involvement, need for surgical treatment is comparably less frequent when compared with young individuals. This can be an advantage when higher morbidity and mortality rates are considered with regard to surgical intervention in an elderly patient [10].

This is first report of clinical aspects of a relatively large group of elderly patients with Crohn's disease in our country. Definitive features, such as nature of involvement, clinical presentation, disease activity, and clinical course demonstrate differences compared with what is observed in younger patients with Crohn's disease. Due to increased comorbidities, organ dysfunction, and possible drug interactions among the elderly, this group of patients should be considered separately and treatment strategies should be tailored according to both disease and host characteristics. As a result of emerging therapies, growing number of elderly patients with IBD can be expected in the future and more studies to define particular features are needed to clearly establish widely accepted management strategies.

Conflict of Interest: None declared.

Financial Disclosure: The authors declared that this study has received no financial support.

Authorship contributions: Concept - F.S., İ.T.; Design F.S., İ.T.; Supervision - F.S., İ.T.; Materials - ; Data collec- tion \&/or processing - İ.T., M.Y.; Analysis and/or interpretation - S.M.S., İ.T.; Literature search - F.S.; Writing - F.S., S.M.S., Y.Ö.Ö., Z.M.Y.K.; Critical review - F.S., Y.Ö.Ö., Z.M.Y.K., E.K.

\section{REFERENCES}

1. Chir AI, Carlomagno N, Grifasi C, Dumani X, Conte D. Lo, Renda A. Clinical management of Crohn's. Disease 2012. p. $1-6$.

2. Gisbert JP, Chaparro M. Systematic review with meta-analysis: inflammatory bowel disease in the elderly. Alimentary Pharmacology \& Therapeutics 2014;39:459-77. Crossre.

3. Hussain SW, Pardi DS. Inflammatory bowel disease in the elderly. Drugs Aging 2010;27:617-24. Crossre

4. Ha C, Katz S. Management of inflammatory bowel disease in the elderly: do biologicals offer a better alternative? Drugs Aging 2013;30:871-6. Crossret

5. Katz S, Feldstein R. Inflammatory bowel disease of the elderly: a wake-up call. Gastroenterol Hepatol (N Y) 2008;4:337-47.

6. Charpentier C, Salleron J, Savoye G, Fumery M, Merle V, Laberenne JE, et al. Natural history of elderly-onset inflammatory bowel disease: a population-based cohort study. Gut 2014;63:423-32. Crossre.

7. Lakatos PL, David G, Pandur T, Erdelyi Z, Mester G, Balogh M, et al. IBD in the elderly population: results from a populationbased study in Western Hungary, 1977-2008. J Crohns Colitis 2011;5:5-13. Crossre]

8. Van Assche G, Dignass A, Panes J, Beaugerie L, Karagiannis J, Allez M, et al. The second European evidence-based Consensus on the diagnosis and management of Crohn's disease: Definitions and diagnosis. J Crohns Colitis 2010;4:7-27. Crossret

9. Heresbach D, Alexandre JL, Bretagne JF, Cruchant E, Dabadie A, Dartois-Hoguin M, et al. Crohn's disease in the over-60 age group: a population based study. Eur J Gastroenterol Hepatol 2004;16:657-64. Crossre.

10. Picco MF, Cangemi JR. Inflammatory bowel disease in the elderly. Gastroenterol Clin North Am 2009;38:447-62. Crossre. 